\title{
Usufructo: efectos de su transmisión entre vivos con referencia a su embargo y subasta
}

\section{POR BELÉN MASCI $(*)$}

\begin{abstract}
Sumario: I. Introducción.- II. Transmisibilidad por actos entre vivos en el Código de Vélez.- III. La transmisibilidad entre vivos en el Código Civil y Comercial.- IV. Embargo y Subasta.- V. Conclusión.- VI. Bibliografía.
\end{abstract}

Resumen: el usufructo es un derecho real que no ha permanecido estático con un perfil netamente asistencial, sino que, por el contrario, el mismo ha adoptado un perfil también económico. Esta ampliación en su función económica social se ha traducido en la tendencia mayoritaria de las legislaciones modernas a flexibilizar la negociabilidad del usufructo y alentar su transferencia. Durante la vigencia del Código velezano, la doctrina mayoritaria entendía que el usufructuario tenía la facultad de ceder solo el ejercicio del usufructo a un tercero. El Código Civil y Comercial de la Nación, en dicha marcada tendencia a promover su expansión en su utilidad y flexibilización, modificó dicha tradición jurídica permitiéndole expresamente al usufructuario, la cesión del mismo Derecho Real de usufructo a un tercero. Este será precisamente el objeto de análisis del presente trabajo, su transmisibilidad por actos entre vivos y sus consecuencias, en cuanto al modo de efectivizar su embargo y ejecución forzada por parte de los acreedores del usufructuario transmitente, según se entienda que se trata de la cesión del derecho o de su ejercicio.

Palabras claves: usufructo - transmisibilidad - embargo - ejecución

Usufruct: Its transferability and its consequences about cautions and forced execution by the creditors of the transferring usufructuary

Abstract: the usufruct is a real right that has not remained static with a purely welfare profile, conversely, it has also adopted an economic profile. This expansion in its economic and social function has resulted in the majority tendency of modern legislation to make the negotiation of the usufruct more flexible and encourage

$\left(^{*}\right)$ Abogada y Escribana, Universidad Nacional de La Plata. Esp. en Derecho Procesal Profundizado, Universidad Notarial Argentina. Esp. en Contratos y Daños, Universidad de Salamanca, España. Prof. de Derechos Reales, Universidad Nacional del Noroeste de Buenos Aires (UNOBA). 
its transfer. During the Velezano code, the majority doctrine understood that the usufructuary had the power to assign only the Exercise of the Usufruct to a third person. The Civil and Commercial Code, in a marked tendency to promote its expansion, modified the legal tradition allowing the usufructuary, the assignment of the same Real Right of Usufruct to a third person. This will be precisely the object of analysis of this paper, its transferability and its consequences, in terms of how effects in cautions and forced execution by the creditors of the transferring usufructuary.

Keywords: real right usufruct - transfer - caution - forded execution

\section{Introducción}

Nuestro máximo codificador, Vélez Sarsfield, inspirándose en el derecho romano clásico ha sido contrario a las desmembraciones al dominio, sin embargo, dentro de ese reducido número hemos encontrado desde el inicio al derecho real de usufructo que, por las bondades que su tipo ofrece, se ha convertido en un derecho real con una innegable utilidad e importancia en nuestro país.

Esta figura nació como un derecho real de un perfil netamente familiar. Pues, como explica el Profesor De Reina Tartiére:

El usufructo nació en Roma, a modo de cláusula testamentaria en beneficio de aquellas personas - básicamente, las mujeres casadas sine manu, esto es, sin haber ingresado en la familia del marido-que, para el ius civile, no contaban con un derecho propio a participar en la sucesión de su consorte. Ante la necesidad de dotar de sustento a la viuda, en similares condiciones a las que rodearon al matrimonio en vida del cónyuge, se ideó el recurso de concederle un goce temporal aunque exclusivo del conjunto o una parte de los bienes de la herencia. Así, en lo formal, al no involucrar una disposición definitiva, no habría de disminuir la cuota de los hijos o de los otros herederos (...) (De Reina Tariére, 2014, p. 1).

Es así que conforme sus orígenes, actualmente sigue teniendo una enorme utilización entre parientes, pues:

Su mayor utilización se alcanza en situaciones de naturaleza hereditaria o sucesoria porque el testador desea favorecer a una persona vitaliciamente, pero no que los bienes pasen después a los herederos de ésta, sino a los suyos propios o a los descendientes de éstos, por lo que en lugar de legar la propiedad lega el usufructo. Es frecuente también en las donaciones, porque el donante no quiere privarse de lo que es fuente de ingresos o rentas mientras viva. Por eso suele donarle la propiedad con reserva de usufructo (Picazo y Gullón, 2016, p. 25). 
Sin embargo, es un derecho real que no ha permanecido estático con un perfil netamente asistencial, sino que, por el contrario, el mismo ha adoptado un perfil también económico, pues es un derecho susceptible de constituirse no solo a título gratuito, sino que también a título oneroso, por contrato e incluso a favor de personas jurídicas. Esta ampliación en su función económica social se ha traducido en la tendencia mayoritaria de las legislaciones modernas a flexibilizar la negociabilidad del usufructo y alentar su transferencia.

Durante la vigencia del código velezano, la doctrina mayoritaria entendía que el usufructuario tenía la facultad de ceder solo el ejercicio del usufructo a un tercero. El Código Civil y Comercial de la Nación (CCiv. y Com.), en dicha marcada tendencia a promover su expansión en su utilidad y flexibilización, modificó dicha tradición jurídica permitiéndole expresamente al usufructuario, la cesión del mismo derecho real de usufructo a un tercero.

Este será precisamente el objeto de análisis del presente trabajo, su transmisibilidad por actos entre vivos y sus consecuencias, en cuanto al modo de efectivizar su embargo y ejecución forzada por parte de los acreedores del usufructuario transmitente, según se entienda que se trata de la cesión del derecho o de su ejercicio.

\section{Transmisibilidad por actos entre vivos en el Código de Vélez}

En vigencia del Código velezano existieron distintas posturas acerca de la transmisibilidad por actos entre vivos.

En un extremo encontramos la postura del Profesor Borda (1978), quien sostenía que la distinción entre cesión del derecho real de usufructo y cesión del ejercicio del derecho real de usufructo no era tal:

El fundamento de la distinción no resulta convincente, al menos en el terreno de las soluciones prácticas. Siendo el usufructo (ya sea constituido por contrato o por testamento) un acto realizado intuitae personae, es evidente que el usufructuario no puede ceder el usufructo liberándose de toda obligación, sin consentimiento del nudo propietario. Y si éste da su consentimiento, bien puede decirse, que en verdad hay dos actos, uno de extinción del usufructo anterior y otro de constitución del nuevo usufructo por el propietario. Cuando el usufructuario actúa por sí solo, sin intervención ninguna del nudo propietario, la cesión que él haga, sea del usufructo, sea del ejercicio, no puede concebirse sino manteniendo íntegramente las responsabilidades que le competen como usufructuario (Borda, 1978, p. 45). 
Para el resto de la doctrina, la distinción entre cesión del derecho real y cesión del ejercicio era tal. Pues, mientras que en la cesión de ejercicio solo se cede un derecho personal, subsistiendo el derecho de usufructo en cabeza del cedente, lo que le permite conservar la disponibilidad de su derecho real, en la enajenación del derecho se transfiere la calidad de usufructuario, con la totalidad de los derechos, deberes y facultades del usufructuario enajenante (Pepe, 2013, p. 1).

Así, partiendo de dicha distinción, las aguas se dividían en la doctrina mayoritaria, que le reconocía al usufructuario la facultad de ceder solo el ejercicio de su derecho real que detentaba (Salvat, 1959; Mariani De Vidal, 2004; Borda, 2012; Musto, 2012; Papaño, Kiper, Dillon y Causse, 2004) y no el derecho real en sí y la doctrina minoritaria para quien el derecho real era transmisible, transferible (Lafaille, 1922; Alterini, 1970).

La primera posición encontraba fundamento principalmente en el que era el artículo 2870 del Código Civil (CC) que establecía: "El usufructuario puede dar en arriendo el usufructo, o ceder el ejercicio de su derecho a título oneroso o gratuito; pero permanece directamente responsable al propietario, lo mismo que el fiador, aun de los menoscabos que tengan los bienes por culpa o negligencia en la persona que le sustituye. Los contratos que celebre terminan al fin del usufructo". Además de invocar la interpretación literal de la norma, coadyuvaba a dicha posición la nota al artículo 2807 CC que establecía refiriéndose al derecho real de usufructo que:

Es también por su naturaleza una propiedad puramente personal incomunicable, que no se puede ceder, e intransmisible por herencia, pues la facultad de usar y gozar de una cosa es esencialmente correlativa a la persona, facultad que se acaba con la persona (...). La cesión que el usufructuario puede hacer a favor de un tercero sin el consentimiento del propietario, no importa sino el ejercicio del derecho, y no el derecho mismo inherente a su individualidad. El cedente será siempre el usufructuario titular, sometido a las mismas obligaciones que pesaban sobre él antes de la cesión.

Siendo un derecho real que tradicionalmente quedaba acotado al ámbito familiar, siendo ordinario que la iniciativa provenía de parte de los padres que pretendían transmitir la nuda propiedad a sus hijos y reservarse el usufructo (Urbaneja, 2018), es decir que se configuraba por una situación especial y personal entre el nudo propietario y el usufructuario, es razonable que nuestra doctrina mayoritaria no permitiera la transmisión del derecho real en sí mismo y solo su ejercicio.

En la tesis opuesta minoritaria, se encontraba el Profesor Lafaille (1944), quien sostenía que:

El titular del usufructo está facultado para transmitir su derecho (...). Sabemos que lo autoriza el art. 2870. Aunque la modalidad de lenguaje 
'(...) ceder el ejercicio de su derecho', pudiera inducir a que se permite transferir las facultades y no el usufructo mismo, pensamos de otro modo, porque la regla es la negociabilidad de todo derecho (art. 1444); de suerte que bastaría con el silencio de la ley. A mayor abundamiento el art. 1449 exceptúa el uso y la habitación, sin mencionar el usufructo (pp. 427-428).

Con buen atino, encontrábamos la posición doctrinaria del Profesor Jorge Alterini (1970), quien loablemente interpretaba que durante el régimen abrogado tanto la cesión del "derecho" de usufructo como la del "ejercicio" del mismo eran viables, y ambas cesiones funcionaban como institutos separados que se regían por normas diferentes. Explicaba: "no debe interpretarse que la norma prohibitiva se encuentra en el artículo 2870 porque Vélez en ese texto se limita a reconocer la cesión del ejercicio, sin pronunciarse sobre la cesión derecho, admitida por el juego de los artículos antes citados" (haciendo referencia a los antiguos artículos 1444 y 1449 del Código Civil de Vélez) (p. 172).

\section{La transmisibilidad entre vivos en el Código Civil y Comercial}

Desde nuestro sistema velezano los derechos han sido, por regla, transmisibles (artículo 1444 CC), constituyendo, como hemos visto, para la opinión mayoritaria, la excepción a la regla el derecho real de usufructo, que solo se permitía la cesión del ejercicio bajo la órbita de los derechos personales.

El actual ordenamiento ratificó la transmisibilidad de los derechos patrimoniales en su artículo 398 del CCiv. y Com. y en la Parte General de los derechos reales reiteró y afirmó dicho principio en su ámbito estableciendo en su artículo 1906 que "todos los derechos reales son transmisibles, excepto disposición legal en contrario".

Siendo directriz del nuevo régimen el mayor aprovechamiento de los bienes y de su valor, con el consecuente incentivo a la circulación de bienes, hizo que de manera expresa se establezca la transmisibilidad del derecho real de usufructo. Así con, esta "vuelta de timón", se ha contribuido a fomentar el aludido perfil más económico que se ha perseguido de este derecho real.

La que había sido, durante el régimen anterior, la postura minoritaria, es la que ahora ha adoptado el Código Civil y Comercial.

El artículo 2142 CCiv. y Com. establece:

Derechos reales y personales. El usufructuario puede transmitir su derecho, pero es su propia vida y no la del adquirente la que determi- 
na el límite máximo de duración del usufructo. Con carácter previo a la transmisión, el adquirente debe dar al nudo propietario garantía suficiente de la conservación y restitución del bien. El usufructuario puede constituir los derechos reales de servidumbre y anticresis, uso y habitación y derechos personales de uso o goce. En ninguno de estos casos el usufructuario se exime de sus responsabilidades frente al nudo propietario.

Es así que ahora, con la permitida enajenación del derecho se transfiere la calidad de usufructuario, con la totalidad de los derechos, deberes y facultades del usufructuario enajenante (Kiper, 2017), y no un simple derecho personal como en el régimen derogado.

De la letra de la norma surgen distintas aristas para considerar: el plazo del derecho real transferido; la garantía obligatoria del adquirente; la responsabilidad del transmitente con respecto al nudo propietario.

En consideración de la primera, lo sentado por la norma en análisis es reiterado por el artículo 2153 CCiv. y Com. que establece que "El usufructo cedido por el usufructuario, no puede durar más allá de la oportunidad prevista para la extinción del usufructo originario". Entiendo razonable que el límite de duración del derecho real transferido sea la vida del transmitente - en el caso de la persona jurídica 50 años- o el plazo menor pactado al momento de su constitución. Pues por el principio de Nemo Plus Iuris nadie puede transmitir un derecho ni mejor ni más extenso del que tiene (artículo 399 CCiv. y Com.), por lo que el derecho real del que es titular el usufructuario será transmitido por el tiempo máximo convenido en el título suficiente o por defecto su vida. Asimismo, contribuye a dicha posición que "de no ser así, se prolongaría de manera extensa el dominio desmembrado, la separación entre la nuda propiedad y el dominio útil podría ser indefinida de verificarse sucesivas cesiones" (Kiper, 2017, p. 89). El profesor Urbaneja es contrario a la opinión que aquí se expone, pues es su estimada opinión:

Separar la titularidad del derecho de la vida de quien determina la duración del mismo contraría los principios del Código de Vélez y del Civil y Comercial, e importaría tanto como incorporar una figura al modo del "cabeza de renta" del contrato oneroso de renta vitalicia, en el que expresamente se admite la posibilidad de considerar con ese carácter a alguien que no sea acreedor, deudor ni beneficiario. No conmueve el argumento de considerar la subsistencia del usufructuario original una derivación del 'nemo plus iuris' (artículo 3270 en el Código de Vélez y artículo 399 en el Código Civil y Comercial de la Nación), precisamente porque a su tenor la vida a tener en cuenta es la de quien sea titular (2015, p. 5). 
En relación con la garantía del adquirente del usufructo por actos entre vivos, en este supuesto la misma es obligatoria, salvo expresa renuncia del nudo propietario. Fíjese que el artículo 2142 CCiv. y Com. es categórico diciendo "debe". Ello se diferencia del supuesto clásico de constitución del usufructo, en donde la garantía aparece como una mera facultad, conforme surge del artículo 2139 CCiv. y Com., que establece: "en el acto de constitución puede establecerse la obligación previa al ingreso en el uso y goce, de otorgar garantía suficiente, por la conservación y restitución de los bienes, una vez extinguido el usufructo." Al respecto, el profesor Ignacio Alterini (2015) ha explicado que la garantía que el pretendido adquirente debe otorgar al nudo propietario antes de la transmisión del derecho no es dispensable por el usufructuario, pero sí por el nudo propietario. Al haber entrega del uso y goce a un tercero que no contrató con el nudo propietario y que el mismo no lo eligió y, sin embargo, quedará ligado, es lógico y plausible que sea obligatoria la garantía suficiente.

Por último, resta atenerse a la responsabilidad del transmitente con respecto al nudo propietario. Se han generado en la doctrina dos posiciones antagónicas. Para Kiper (2017), Mariani de Vidal y Abella (2016) el usufructuario transmitente no se exime de las responsabilidades con respecto al nudo propietario. Si no se libera por constituir un derecho de uso o una locación, se puede inferir que tampoco lo hará por transmitir el derecho de usufructo. En posición en contrario se encuentran los profesores Urbaneja (2018) y Frontini (2015), para quienes la obligación de garantía del adquirente genera que el transmitente se libere de responsabilidad. Así, Frontini (2015) expresa que "en la transferencia voluntaria o forzada, el otorgamiento por el adquirente de garantías suficientes de conservación y restitución del objeto, trae como consecuencia que la transferencia del usufructo libera de responsabilidad al enajenante o ejecutado luego de la transferencia, responsabilidad que asume el adquirente" (p. 3).

En vista a las posiciones mayoritarias, actualmente es posible la transferencia del derecho real de usufructo, pero no debemos olvidar que también se podría ceder el ejercicio del derecho real de usufructo bajo la órbita de los derechos personales, como por ejemplo bajo la figura de un comodato o una locación (Malizia, 2016). El artículo 2142 CCiv. y Com., tercer párrafo dice: “(...) El usufructuario puede constituir los derechos reales de servidumbre y anticresis, uso y habitación $y$ derechos personales de uso o goce".

Lo cierto es que si bien estoy conforme con la doctrina mayoritaria acerca del plazo del usufructo transmitido y la responsabilidad mantenida por el transmitente, como explica el profesor Urbaneja (2015), "si la duración del usufructo sería la de su titular originario y el transmitente continuaría siendo responsable frente al nudo propietario, se trataría de una disquisición puramente terminológica: 
llámese cesión del derecho o cesión del ejercicio, no habría diferencia entre ambos y la controversia sería absolutamente estéril" (p. 5).

Pareciera que, desde este punto de vista, se sostendría similarmente la postura de Borda (1978) en vigencia del régimen anterior, no habiendo diferencias entre la cesión del derecho y el ejercicio en cuanto a las aristas constitutivas de la transferibilidad entre nudo propietario - usufructuario transmitente- usufructuario adquirente, en el ámbito de las transferencias que han sido voluntarias.

De lo que no podrá caber duda alguna que el terreno de las diferencias importantes, prácticas y patrimoniales, se encuentran en el ámbito de las transferencias forzadas, en ejecuciones de acreedores - tanto individuales como colectivas-, de un derecho real de usufructo que ha sido cedido como tal o bien solo su ejercicio.

\section{Embargo y subasta}

La vida normal de una obligación comprende su etapa de cumplimiento voluntario. Sin embargo, la práctica muestra los incontables procesos de conocimiento o de ejecución - tanto individuales como colectivos- en donde los acreedores buscan hacer efectiva la famosa máxima que establece que "el patrimonio es la garantía común de los acreedores". En este sentido, puede suscitarse que, dentro del activo de ese patrimonio, encontremos el caso de la existencia de la titularidad en el deudor de un derecho real de usufructo y el acreedor busque la satisfacción de su crédito a partir del mismo.

En este contexto se puede suscitar que judicialmente se establezca un embargo sobre el usufructo, sobre todo será solicitado por los acreedores en procesos individuales para lograr la prioridad del primer embargante (artículo 745 CCiv. y Com.) y establecido judicialmente en los procesos de ejecuciones forzosas mayormente individuales. Podetti (1968) define al embargo como "la medida judicial que afecta un bien o bienes determinados, de un deudor o presunto deudor al pago eventual de un crédito, individualizándolo y limitando las facultades de disposición y goce" (p. 205). Así, cuando el embargo preventivo o ejecutivo se convierte en ejecutorio, tendiente a efectivizar el cumplimiento del crédito, se buscará con aquellos bienes - en este caso objeto de usufructo-, lisa y llanamente, pagar al acreedor mediante la subasta. Lo mismo sucede en los procesos colectivos, en donde el juez puede disponer medidas cautelares - aunque generalmente la inhibición general de bienes-, y se llega a su final con la subasta de los bienes objeto del derecho real de usufructo. En estos casos, surge la problemática acerca de cuál será el asiento del embargo y cómo efectivizar el cobro por los acreedores, de manera forzada, a partir de este derecho real. La forma de efectivizar el embargo y posterior ejecución forzada se diferenciará conforme el mismo pueda recaer bien 
solo sobre el ejercicio del derecho real de usufructo (Código Civil), bien sobre el derecho real de usufructo en sí (Código Civil y Comercial).

\section{IV.1. Régimen velezano}

El artículo 2908 CC decía: "Los acreedores del usufructuario pueden pedir que se le embargue el usufructo y se les pague con él, prestando la fianza suficiente de conservación y restitución de la cosa tenida en usufructo". De la simple lectura de esta norma parecería que el embargo puede recaer sobre el derecho real de usufructo considerado en sí mismo; sin embargo, realizando una interpretación armónica con el artículo 2870 CC que solo permitía la cesión del ejercicio del derecho real de usufructo por el usufructuario a un tercero y no del derecho real en sí, los acreedores del usufructuario podían embargar su derecho y cobrarse a partir del mismo, pero jamás proceder a su subasta ya que la misma equivaldría a la adquisición del derecho real de usufructo por un tercero, supuesto que estaba vedado. Si el usufructuario no puede, por sí, transmitir el derecho del que es titular, mucho menos podría lograrse ese resultado por la vía indirecta de la ejecución forzada. Así lo explicaba la profesora Mariani de Vidal (1997):

La regla del artículo (2908) no debe ser entendida como que los acreedores del usufructuario pasan a ser ellos los titulares del derecho real. Como se sabe, el usufructo no es cesible, permaneciendo siempre el usufructuario como responsable frente al nudo propietario (artículo 2870). Lo que sí es transmisible es el ejercicio del derecho de usufructo y, sobre tal base, es que los acreedores pueden, como dice el artículo 2908, solicitar su embargo y que se les pague con él. Hasta tal límite la ley confiere derechos a los acreedores del usufructuario. No podrían ellos pedir la venta del usufructo, ni requerir que se les adjudique en pago de lo que se debe (p. 1018).

Habiendo quedado en claro la imposibilidad de proceder a la subasta del usufructo, es importante dejar en claro el modo de efectivizarse el embargo trabado por los acreedores del usufructuario. Así, se ha entendido que se efectivizaba mediante el cobro de su producido, bien sea quedando las cosas en manos del deudor, debiendo este entregar su producido hasta la cancelación del crédito; o que el acreedor embargante pueda asumir el usufructo de la cosa y percibir sus frutos, previo otorgamiento de fianza, y pagada la deuda, el usufructuario podía nuevamente ejercitar sus derechos (Lavalle Cobo y Fornari, 2007). En este segundo supuesto, los acreedores embargantes solicitarían el secuestro del objeto del usufructo, previa caución, con la posibilidad de que el juez designe un administrador judicial para que perciba los frutos (Guardiola, 2014). 
Tenemos que recordar que, en el usufructo, el nudo propietario cede el uso y goce a quien será el usufructuario y sus facultades son amplias, pues el usufructuario puede usar, percibir los frutos naturales, industriales o civiles, y gozar de los objetos sobre que se establece el usufructo, como el propietario mismo (artículo 2863 CC). Cuando el usufructuario destine el objeto a darlo en locación, arrendamiento, o se dedique a cualquier emprendimiento como lo podría ser el uso y goce de un viñedo, el acreedor no tendrá mayores complicaciones y procederá a su embargo y cobro a partir de los frutos señalados. Sin embargo, en otros casos podría suceder que el objeto en usufructo no genere frutos, como sería los casos que el usufructuario habite el inmueble. En esos casos la jurisprudencia ha establecido la imposibilidad de los acreedores a cobrarse a partir del embargo del ejercicio del usufructo. Si la cosa no ha sido arrendada, sea que se encuentre desocupada o que viva en ella el usufructuario, el embargo debiera ser desestimado por falta de asiento sobre el cual recaer (Pettis, 2018). Así, en los autos de la Cámara Civil y Comercial (CCiv. de Junín, Expte. No 50061 "Athier S.A. y Otros c. Castro Elsa Esther y otro S. Ejecutivo", sentencia de abril 2011 y julio 2013, la parte actora había solicitado que se excluya al ejecutado demandado titular del derecho real de usufructo embargado del inmueble subastado en autos, a fin de que la embargante pueda asumir el usufructo de la cosa y así percibir los frutos, cobrándose el crédito aún pendiente, para luego reintegrar el ejercicio al usufructuario, solicitud que le fue denegada porque el deudor habitaba el inmueble sobre el que tiene un derecho real de usufructo, no surgiendo de los antecedentes de autos que dicho bien genere frutos civiles sobre los que pueda satisfacer su crédito el acreedor embargante. El pronunciamiento deja entrever que, aunque la doctrina había encontrado el modo de proteger al acreedor embargante dándole una posibilidad en el modo de efectivizar el embargo, si el objeto del usufructo no producía frutos, la cesión del ejercicio tampoco procedía en los hechos. Semejante pronunciamiento fue un fallo de la CCiv. San Martín, sala II, 50823 RSD-126-2 S 7-5-2002, “Daversa, Virginia B. c. Widelhofer, Mario Juan s/ejecutivo", que estableció que

(...) la subasta de derechos y acciones es admisible en tanto tenga por objeto créditos claros y precisos, y no cuando resulten inciertos, especulativos y de dudosa realización. En consecuencia, no cabe ordenar la subasta de un derecho real de usufructo, atendiendo a las restricciones que pesan sobre el acreedor embargante de ese derecho, quien sólo está autorizado a cobrarse con el producido del ejercicio de ese derecho real y resarcirse mediante los frutos naturales civiles e industriales percibidos (artículos 2863, 2264, 583, 2425 y 2865, Cód. Civil) y los frutos adquiridos por su separación de la sustancia misma de la cosa (artículos 2866, 2444 y concs., Cód. Civil). En ese contexto, cabe colegir que no sólo se aprecia una insalvable dificultad para establecer el contenido económico de esos derechos, sino que, lo que es más grave aún, no puede siquiera vaticinarse con un grado mínimo de certeza la 
obtención de ese tipo de elementos susceptibles de ser embargados o, en su caso, de ser ejecutados forzadamente.

En otros casos, nuestra jurisprudencia muestra que, existiendo pruebas en la causa, se evaluaron qué frutos generaba el objeto sobre el que recaía el usufructo para el cobro a partir de los mismos de los acreedores, permitiéndoles así su ejercicio. En los autos de la Cámara Nacional Civil y Comercial, sala C, "Wasserman, Ulrico s/concurso", febr. 13-1975, ED, 62-182/3, se estableció que

El usufructo por su propia naturaleza no es cesible y lo único que se puede transferir por parte del usufructuario es el ejercicio de ese derecho en forma onerosa o gratuita (art. 2870 y su nota Cód. Civil; Salvat, Obligaciones en general, t. III, núm. 2329 y Derechos reales, t. III, núm. 1575; Rezzónico, Estudio de los contratos, t. I, págs. 562 y 566, nota 40, párr. final; Peña Guzmán, Derechos Reales, núms. 1384 y 1456) y los acreedores no se subrogaron al usufructuario en el derecho, sino que obtuvieron la facultad de cobrarse con los alquileres ingresados en la masa, continuando aquél como titular del derecho; luego, una vez decretada su rehabilitación, corresponde que esos alquileres sean reingresados a su beneficiario, ya que el derecho de la masa no puede extenderse hasta después de ordenada aquella.

Igual sucedió en una causa de la Cámara Comercial, Laboral y de Minería de General Pico, con fecha 15-2-06, autos "Nicolau, Horacio S. c. Sueldo, Luis E. y otro", LL, Patagonia 2006 (junio), que estableció "El acreedor puede solicitar que se trabe embargo sobre el ejercicio del usufructo del que es titular el ejecutado y no sobre el usufructo mismo, de acuerdo con lo previsto en los arts. 2870 y 2908 del Cód. Civil, dado que, si bien el usufructo no es cesible, puede transmitirse su ejercicio a través de una futura locación y los acreedores pueden percibir sus créditos a través de los alquileres derivados de dicha transmisión".

La imposibilidad de proceder a la subasta y la única opción de que los acreedores embargantes se cobren con lo producido por el objeto del usufructo ha traído casos en donde si el usufructo no ofrecía frutos, los acreedores no tengan "a partir de qué cobrarse" y termine siendo en vano el intento del embargo para cobrar sus acreencias, precisamente por carecer el embargo de asiento. Esta era la gran dificultad que traía el régimen anterior con la imposibilidad de la cesión del derecho real considerado en sí mismo.

\section{IV.2. El Código Civil y Comercial}

El ordenamiento vigente permite ahora sí, la transferencia no solo del ejercicio del derecho real de usufructo, sino que también la cesión del derecho real de 
usufructo por parte del usufructuario a un tercero. De esta forma, el objeto del embargo, hacerlo efectivo y cobrar acreencias sobre el mismo, ha hecho un total giro en beneficio de los acreedores del usufructuario. Sin hesitación alguna el embargo tendrá como asiento el derecho real de usufructo considerado en sí mismo y se efectivizará será mediante la subasta judicial, que indefectiblemente originará la transferencia forzada del derecho al adquirente del mismo en ese acto. Las Jornadas Nacionales de Derecho Civil de Bahía Blanca 2015 establecieron De lege lata por unanimidad que "el CCiv y Com. no solo prevé la transmisibilidad voluntaria, sino también forzosa, mediante subasta pública, en ejecución individual o colectiva. En este caso, el nudo propietario debe ser citado al proceso".

El artículo 2144 CCiv. y Com. establece que "si el acreedor del usufructuario ejecuta el derecho de usufructo, el adquirente del usufructo debe dar garantía suficiente al nudo propietario de la conservación y restitución de los bienes". Vemos que la garantía es exigida entonces no solo en los casos de transmisión voluntaria (artículo 2142 CCiv. y Com.), sino que también en los casos en donde la transmisión es forzosa mediante la subasta (artículo 2144 CCiv. y Com.); en ambos casos la garantía resulta obligatoria “(...) debe dar (...)”. Aquí el Código sigue la línea del artículo $1908 \mathrm{CC}$, pero con otro alcance, ya que se interpretaba que el usufructo seguía siéndolo a pesar del embargo y que el acreedor embargaba el derecho a percibir los frutos. Ahora se permite la ejecución del derecho (Kiper, 2017).

El juez de la ejecución deberá citar previamente a la subasta al nudo propietario a fin que este, no solo controle el proceso de ejecución, sino también para que una vez operada la subasta, la adjudicación al mejor postor, la posterior aprobación de la subasta, ésta se condicione a la expresa conformidad por parte del nudo propietario respecto de la suficiencia de la garantía ofrecida por dicho adquirente, la cual deberá ser ofrecida al momento del depósito del valor de adquisición de dicho derecho real de usufructo y constituirla (Colotto, 2015, p. 2).

Ello es razonable si se piensa que el mismo pasará forzosamente a encontrarse ligado con un nuevo usufructuario no convenido a su elección.

La venta deberá ser ordenada por vía judicial en el marco de un proceso en el cual el acreedor reclame el cumplimiento de un crédito a su favor, razón por la cual el embargo puede ostentar la categoría de preventivo, ejecutivo, o ejecutorio, según la clase de proceso que se hubiere iniciado y el estado procesal de la causa (Kiper, 2017).

Producida la venta en subasta del usufructo, el acreedor embargante adquirirá la titularidad del derecho real de usufructo, por el plazo establecido para el transmitente y quedando el mismo responsable — conforme la posición mayoritaria-. 
Como expresa la profesora Liliana E. Abreut de Begher (2015):

Esta modificación soluciona un tema muy conflictivo en materia de propiedad horizontal cuando el usufructuario no abonaba las expensas comunes y la subasta de la nuda propiedad no solucionaba el problema central que impactaba en el desenvolvimiento económico normal del consorcio. Bajo el nuevo código frente a una ejecución se subastará el dominio útil, conservando el titular dominial la nuda propiedad (p. 3).

En general, con la nueva regulación dejan de existir los problemas a los acreedores que se ocasionaban cuando el uso y goce del transmitente no generaba frutos y el embargo carecía de asiento, como los casos en el que el inmueble en usufructo estaba destinado para la vivienda. Pues ahora, al permitirse la cesión del derecho real, el transmitente entrega la titularidad del mismo y dicho uso y goce destinado a morar. Sin embargo, ello encontraría coto en los casos en donde el usufructuario transmitente haya protegido al inmueble bajo el régimen de protección a la vivienda (artículo 244 CCiv. y Com. y ss.) y pueda excepcionarse la transmisión del derecho real. Pues no hay dudas de la posibilidad de la aludida protección; en las Jornadas de Derecho civil de 2015 de lege lata se estableció que: "El usufructuario puede afectar el inmueble objeto de su derecho al régimen de vivienda previsto por los arts. 244 y ss. del CCiv. y Com., si concurren los requisitos exigidos por dichas normas. En tal caso, la afectación al régimen de vivienda durará solo mientras exista el usufructo, salvo que el dominio se consolide en cabeza del usufructuario (Unanimidad)".

Es por ello que el usufructuario que quiera proteger su uso y goce destinado exclusivamente a vivienda de las acciones de los acreedores, es conveniente que opte por la utilización del derecho real de habitación, que es intuito personae e intransmisible e inejecutable, para evitar la penosa situación de tener que verse obligado a una transmisión forzosa en virtud de una ejecución.

Por último, es importante hacer mención a la inconsistencia generada por el artículo 744 inc. E del CCiv. y Com., que indica que el usufructo es inejecutable, excepto en el caso del artículo 2144 CCiv. y Com., y este último se limita a señalar la posibilidad de ejecutar el usufructo que tienen los acreedores del usufructuario, sin establecer supuestos para llevarla a cabo. Desde un extremo encontramos la posición doctrinaria de los profesores Corna, Fossaceca y Amestoy (2015) que han sostenido:

Que el usufructo es inembargable, salvo los frutos sobrantes, cuando es utilizado para la subsistencia del deudor y su familia por no tener otros bienes que llenen ese cometido. Cuando resulta parcialmente 
empleado para tal fin, por no alcanzar los bienes que tiene el deudor, se debe embargar los frutos sobrantes. Cuando el deudor posee otros bienes para su subsistencia y la de su familia, se torna embargable y ejecutable por los acreedores, con el alcance del artículo 2144 (p. 3).

Desde otro extremo, y en la postura que se propicia, el profesor Urbaneja (2018) enseña que el artículo 744 inc. E CCiv. y Com. queda neutralizado: el usufructo es ejecutable en todos los casos conforme los principios generales del incumplimiento.

\section{Conclusión}

En la introducción al presente trabajo me he propuesto visualizar las consecuencias que acarrea la facultad de la transmisibilidad del ejercicio o del derecho real de usufructo en cuanto a la posibilidad de su embargo y subasta.

Los efectos diversos han quedado demostrados, pues en vigencia del régimen anterior, en donde la doctrina mayoritaria entendía que lo que se cedía era el ejercicio del usufructo, el embargo se hacía efectivo a partir del cobro de los frutos y estaba vedada la subasta porque irremediablemente traería la vedada transmisibilidad del derecho a un tercero. Vimos que muchas veces, al no generar frutos, el derecho del acreedor embargante quedaba en el vacío por no contar con asiento.

Por el contrario, cuando lo que se trasmite es el derecho real de usufructo establecido por el régimen actual, no habrá ningún problema para que el cobro de la acreencia se haga efectiva mediante la venta en subasta judicial y que el tercero pase a ser titular del derecho real de usufructo del transmitente, en los términos que este lo hubiese pactado. En estos casos no habrá dificultad en la valuación de los frutos, quedando restringido solamente el derecho del acreedor cuando el objeto del usufructo recaiga sobre un inmueble sometido al régimen de protección a la vivienda.

Entiendo que la reforma traída por el Código Civil y Comercial no ofrece reparos importantes, pues los derechos del nudo propietario siguen siendo protegidos mediante la obligatoriedad de una garantía otorgada por el adquirente y sobre todo porque será el plazo/vida del transmitente el tiempo en que durará el derecho en cabeza del tercero, como asimismo que el transmitente continúa obligado frente al nudo propietario. Con dichas condiciones el carácter de personal del usufructo sigue latente, porque el vínculo "especial" entre el nudo propietario y el usufructuario por él convenido continua en vigencia y, asimismo, mejora las condiciones de cobro de los acreedores del usufructuario que ahora podrán hacer valer sus derechos con mayor flexibilidad y tal vez, mayor éxito. 
El usufructo es un derecho real que, si bien ha sido apuntado por la doctrina una decreciente importancia temporal (Lafaille, 1922)(1), ha terminado por demostrar su importante utilidad, llegándose incluso a reconocer que la eficacia para satisfacer las necesidades económica-sociales que tradicionalmente ha satisfecho la locación pueden ser cumplimentadas con eficacia a través del usufructo (Alterini, 1970; Alterini, 2012).

A partir del ordenamiento jurídico vigente se ha buscado impulsar su utilidad permitiendo la contratación del usufructo en el ámbito de los derechos personales y, asimismo, la transmisibilidad del derecho real en sí. Sin embargo, lamentablemente al ser ahora un derecho real susceptible de ejecución forzada desalentará su constitución y entrarán a jugar en el tráfico inmobiliario los derechos reales de uso y habitación, tantas veces olvidados, por ser inembargables e inejecutables. Si bien el intento de su impulso de negociabilidad podría verse frustrado por la nueva reforma, estimo que el resultado del cambio ha sido loable, siguiendo nuestro ordenamiento la tendencia de las modernas legislaciones, respetando el carácter personal del derecho real de usufructo y otorgando mayor efectividad a los derechos de cobro por parte de los acreedores. Bienvenida la transmisibilidad.

\section{Bibliografía}

Abreut de Begher, L. (2015). El usufructo: Sus caracteres frente al nuevo Código Civil y Comercial. Congreso Nacional de Derecho Civil 2015, comisión 5, Derechos Reales. Recuperado de https://jndcbahiablanca2015.com/wp-content/ uploads/2015/09/Abreut-de-Begher_EL-USUFRUCTO.pdf [Fecha de consulta: $15 / 05 / 2021]$.

Alterini, I. E. (2015). Límites de la Transmisión del Derecho Real de Usufructo. Jornadas Nacionales de Derecho Civil Bahía Blanca 2015, ponencia Comisión No 5, Derechos Reales. Recuperado de https://jndcbahiablanca2015.com/wpcontent/uploads/2015/10/Alterini_Limites-transmision.pdf [Fecha de consulta: 15/05/2021].

Alterini, J. H. (1970). La locación y los derechos reales con función equivalente. La Plata: Editora Platense S.R.L.

Alterini, J. H. (2012). Usufructo. Revista del Notariado, 809. La Ley Online: AR/ DOC/359/2012 [Fecha de consulta: 15/05/2021].

(1) Lafaille explicaba "que el usufructo había quedo limitado al caso de los padres, a quienes incumbe por ministerio de ley. Pocas veces lo encontramos en las disposiciones testamentarias, y menos todavía, instituito por actos entre vivos" (p. 406). 
Borda, G. (1978). Tratado de Derecho Civil. Derechos Reales II. Segunda Edición actualizada y ampliada. Buenos Aires: Abeledo Perrot.

Borda, G. (2012). Manual de Derechos Reales, actualizado por Delfina Borda. Buenos Aires: Fondo Editorial de Derecho y Economía.

Corna, P. M.; Amestoy, P. K. y Fossaseca, C. A. (2015). ¿Presenta El Usufructo Carácter Alimentario? Discrepancias en el Nuevo Código Civil y Comercial de La Nación. Jornadas de Derecho Civil 2015, comisión 5: Derechos Reales. Recuperado de https://jndcbahiablanca2015.com/wp-content/uploads/2015/09/Corna-yotros_\%C2\%BFPRESENTA.pdf [Fecha de consulta: 15/5/2021].

De Reina Tartiére, G. L. (2014). El tipo del usufructo como derecho real desde el orden jurídico español. Revista del Notariado 915, 01/01/2014, 127. Cita Online: AR/DOC/2019/2016.

Frontini, E. M. (2015). Transmisión del Derecho de Usufructo. Jornadas Nacionales de Derecho Civil Bahía Blanca 2015, ponencia Comisión n5, Derechos Reales. Recuperado de https://jndcbahiablanca2015.com/wp content/uploads/2015/09/ Frontini_TRANSMISI\%C3\%93N.pdf [Fecha de consulta: 17/05/2021].

Guardiola, J. J. (2014). Transmisibilidad del usufructo (Conclusión del diario del 20 de agosto de 2014). El Derecho, No 13.550.

Kiper, C. (2017). Tratado de Derechos Reales. Santa Fe: Rubinzal Culzoni.

Lafaille, H. (1922). Derecho Civil Tomo IV, Tratado de los Derechos Reales, Vol. II. Buenos Aires: Compañía Argentina de Editores S.R.L.

Lafaille, H. (1944). Derecho Civil, Tomo IV, Tratado de los Derechos Reales, Vol. II. Buenos Aires: Compañía Argentina de Editores S.R.L.

Lavalle Cobo, J. A. y Fornari, M. (2007). Usufructo. En E. Zannoni (dir.) y A. Kemelmajer de Carlucci (coord.), Código Civil Comentado, T. 11. Buenos Aires: Astrea.

Diez-Picazo, L. y Gullón, A. (2016). Sistema de Derecho civil: Volumen III (Tomo II) Derechos Reales en Particular. España: Biblioteca Universitaria De Editorial Tecnos.

Malizia, R. (2016). Usufructo. En R. Lorenzetti, Código Civil y Comercial de la Nación Comentado, Tomo IX. Santa Fe: Rubinzal Culzoni Editores.

Mariani de Vidal, M. (1997). Usufructo. En A. Bueres (dir.) E. Highton (coord.) Código Civil Comentado, T. 5. Buenos Aires: Hammurabi. 
Mariani de Vidal, M. (2004). Derechos Reales, Tomo III. Buenos Aires: Zavalía.

Mariani de Vidal, M., Abella, A. (2016). Derechos Reales en el Código Civil y Comercial. Buenos Aires: Zavalía.

Musto, N. J. (2012). Derechos Reales, Tomo II. Buenos Aires: Editorial Astrea.

Papaño, R. J.; Kiper, C. M.; Dillon, G. A. y Causse, J. R. (2004). Derechos reales. $2^{\mathrm{a}}$ ed. Buenos Aires: Astrea.

Pepe, M. (2013). Transferencia del usufructo. La Ley, 3-E, 785 cita Online: AR/ DOC/2558/2013.

Pettis, C. R. (2008). El embargo y el derecho real de usufructo. MJ-DOC-3411-AR | MJD3411

Podetti, R. J. (1968). Derecho Procesal Civil, Comercial y Laboral, t. VII-A, Tratado de las ejecuciones, $2^{\mathrm{a}}$ ed. actualizada por el Dr. Víctor A. Guerrero Leconte. Buenos Aires: Ediar.

Salvat, R. M., (1959). Tratado de derecho civil argentino. Derechos reales. $4^{\mathrm{a}}$ ed. actualizada por Manuel J. Argañarás. Buenos Aires: Tipográfica Editora Argentina.

Urbaneja, M. (2018). Usufructo, Uso y Habitación: aspectos civiles, notariales y registrales de su nueva función económica. LXVI Seminario Laureano Arturo Moreira, Academia Nacional del Notariado.

Urbaneja, M. (2015). Causas de adquisición y de extinción del usufructo en el Código Civil y Comercial de la Nación. SJA. Cita Online: AR/DOC/5548/2015.

Urbaneja, M, (2018). Usufructo, uso y habitación: aspectos civiles, notariales y registrales de su nueva función económica. LXXXVI Seminario Laureano Arturo Moreira, Academia Nacional del Notariado.

Fecha de recepción: 30-03-2021 Fecha de aceptación: 28-09-2021 
